\title{
A model of ablation-dominated medial moraines and the generation of debris-mantled glacier snouts
}

\author{
Robert S. ANDERson \\ Department of Earth Sciences and Institute of Tectonics, University of California, Santa Cruz, California 95064, U.S.A.
}

\begin{abstract}
Medial moraines form striking dark stripes that widen non-linearly, steepen laterally and increase in relief down-glacier from the equilibrium line. Coalescence of these low-ablation-rate features can feed back strongly on the mass balance of a glacier snout. Ablation-dominated medial moraines originate from debris delivered to glacier margins, producing a debris-rich septum between tributary streams of ice below their confluence. Emergence of this ice below the equilibrium line delivers debris to the glacier surface, which then moves down local slopes of evolving morainal topography. A quantitative description of moraine evolution requires specification of the debris concentration field within the glacier, treatment of the melt-rate dependence on debris thickness, and characterization of processes that transport debris once it emerges onto the ice surface. Debris concentration at glacier tributary junctions scales with the erosion rates and the lengths of the tributary-valley walls, and inversely with the tributary ice speeds. Melt rate is damped exponentially by debris, with a $\sim 10 \mathrm{~cm}$ decay scale. Debris flux across the glacier surface scales with the product of debris thickness and local slope. Analytical and numerical results show that medial moraines should develop cross-glacier profiles with parabolic crests and linear slopes, and should widen with age and hence distance downglacier. Debris should be both thin and uniform over the moraine. Observed faster-thanlinear growth of moraine widths with distance reflects the increasing ablation rate downglacier. Increase in medial moraine cover reduces the local average ablation rate, allowing the glacier to extend further down-valley than meteorology alone would suggest. This feedback is especially effective when moraines merge.
\end{abstract}

\section{LIST OF SYMBOLS}

The second column indicates the unit, if any.

$b \quad L / T \quad$ Ablation rate

$b_{0} \quad L / T \quad$ Ablation rate on bare ice

$b^{\prime} \quad L / T \quad$ Ablation rate reduced by presence of debris mantle

$B \quad L / T \quad$ Local mass balance on the glacier

c $L^{3} / L^{3} \quad$ Volumetric concentration of debris in the glacial ice

$D \quad L \quad$ Glast diameter

$G \quad L \quad$ Glacier thickness

$H \quad L \quad$ Thickness of debris over a small element of ice

$H_{\text {ss }} L \quad$ Steady-state uniform debris thickness on a medial moraine

$H_{*} \quad L \quad$ Length scale for decay of ablation rate with debris thickness

$L \quad L \quad$ Pedestal height

$N \quad$ Number of tributary glaciers

$Q \quad L^{3} / L T$ Volumetric debris discharge rate per unit width of slope

$p \quad$ Porosity of morainal debris

$R_{\mathrm{m}} \quad L \quad$ Local moraine relief (moraine top to adjacent bare ice)

$R_{\mathrm{v}} \quad L \quad$ Local valley relief (ridge top to glacier bed)

$U \quad L / T \quad$ Down-valley surface ice speed

$\langle U\rangle L / T$ Mean surface ice speed between ELA crossing and position $\mathrm{X}$

$\begin{array}{ll}V & L^{3} \\ W & L \\ W_{0} & L \\ W_{\mathrm{g}} & L \\ x & L \\ y & L \\ \alpha & \\ \beta & \\ & \\ \delta & L \\ \epsilon_{\mathrm{g}} & L / T \\ \epsilon_{\mathrm{w}} & L / T \\ \gamma & \\ & \\ \eta & 1 / T \\ \theta & \\ & \\ \kappa & L^{2} / T \\ \Lambda & L \\ \tau & T\end{array}$

Volume of a clast

Width of the medial moraine

Width of debris-rich septum of ice

Width of the glacier

Down-glacier distance

Cross-glacier distance

Local slope angle

Enhancement of clast step length in numbers of clast diameters

Step length of clasts on the ice surface

Erosion rate of glacier bed

Erosion rate of tributary valley wall

Scales critical pedestal height for topple in terms of clast diameters

Horizontal gradient in the bare-ice ablation rate

Azimuth of clast topple $(\theta=0)$ is directly down fall line)

Topographic diffusivity of debris

Length of a tributary glacier

Time-scale for toppling of rock-capped ice pedestals

Fraction of glacial ice occupied by debris-rich septum 


\section{INTRODUGTION}

Medial moraines are longitudinal bands of thin debris cover on a glacier's surface. They stand as ridges above the adjacent bare ice because the debris suppresses the melt rate of the glacier surface. Medial moraines widen significantly downglacier (Figs 1 and 2). On long glaciers with many tributaries, this widening and the resulting merging of moraines can result in significant if not complete debris cover of the glacier surface in the lower part of the ablation zone. The resulting modification of the mass-balance profile can lead to dramatically enhanced glacial extent, altered accumulation-area ratios and increased lags between climatic forcing and glacial responses (see summary in Kirkbride, 1995). In this paper a simple model of the evolution of medial moraines is presented as a means of providing a quantitative context for this problem.

The origin of the medial morainal debris varies from moraine to moraine and has resulted in the classification of medial moraines (Eyles and Rogerson, 1978; Gomez and Small, 1985). In all but the anomalous case of large landslides delivering debris well out onto the glacier surface, the debris comprising medial moraines results from the emergence of debris from within the glacier. The ultimate origin of this debris is either the walls above tributary glaciers upstream or the bedrock beneath the glacier. On any particular moraine, the origin is best judged by lithology and by angularity of the clasts. Most moraines show the highly angular blocks

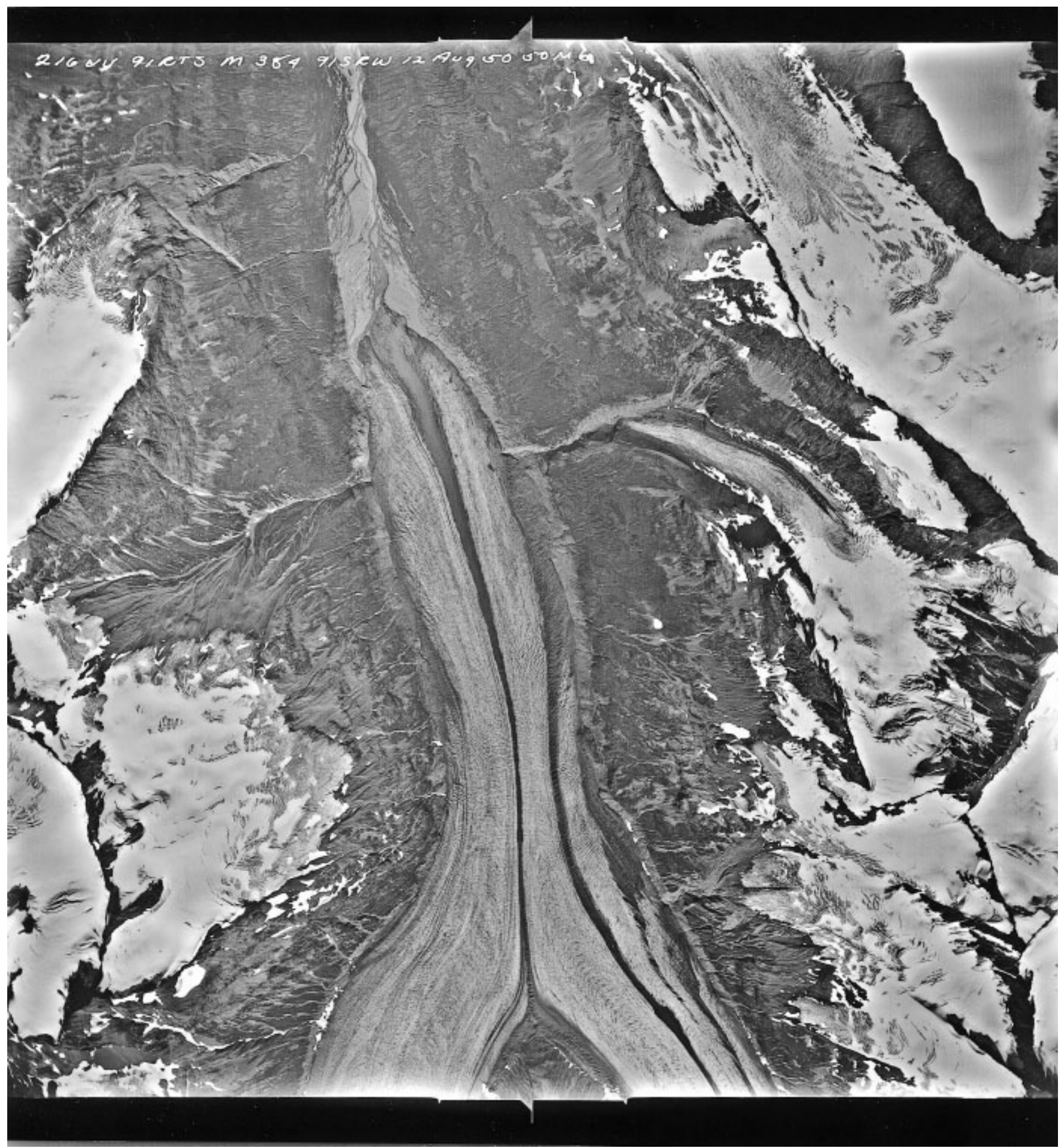

Fig. 1. (a) Vertical air photo, 12 August 1950, of Wortmanns Glacier, near Valdez, Alaska (courtesy of the U.S. Geological Survey (USGS) Geodata Center archives, from the USGS Ice and Climate Project, Tacoma, WA). Note dramatic widening of the major central medial moraine with distance down-ice (plotted in Fig. 2). 
indicative of their origin through hillslope processes delivering talus and rock fall to the edges of the glacier. Many medial moraines, including the ablation-dominated moraines on which this paper is focused, may be traced up-glacier to a confluence of tributary glaciers. If the confluence is below the equilibrium-line altitude (ELA), then the lateral moraines from each of the tributaries merge to form a medial moraine. If the confluence is above the ELA, the debris does not appear on the ice surface until some distance down-glacier from the ELA, where the septum of debris-rich ice emerges from beneath the ice that accumulated above it.

The chief characteristics of ablation-dominated medial moraines that serve as constraints on any model of medial moraines and their influence on the glacial ablation pattern may be summarized as follows. Medial moraine width generally increases down-glacier. The most common exception to this rule is in regions of strong local convergence of ice, as is common immediately down-ice from a tributary junction (see Gudmundsson (1999) for discussion of the local glacier flow field). An example that illustrates both of these phenomena is the prominent medial moraine of Wortmanns Glacier, Chugach Range, Alaska, U.S.A. (Fig. 1). For about $1 \mathrm{~km}$ downstream from the confluence, a distance comparable to the width of the joining tributaries, the moraine width appears to decline slightly. Beyond this, the moraine widens non-linearly toward its widest point at the terminus, where it comprises more than half of the glacier width. This non-linear growth of medial moraines appears to be common (e.g. Fig. 2).

Growth in width of a moraine is typically accompanied by increase in local relief of the moraine above adjacent debris-free ice. On an extensive medial moraine in the center of East Fork Toklat Glacier, Denali National Park, Alaska, the width and relief increase is accompanied by an increase in the maximum cross-glacier slope of the feature down-ice, reaching nearly $30^{\circ}$ near the terminus (Fig. 3).

Interestingly, where probed, the morainal debris is relatively uniform in thickness, reaching only a few centimeters. The debris is often only one clast diameter thick. For example, on East Fork Toklat Glacier, cross-sections of the medial moraine exposed by transverse crevasses displayed an almost perfectly uniform layer of debris approximately $5 \mathrm{~cm}$ thick. Exceptions to this observation are either local, at the bases of steep slopes bounding small supraglacial water channels, or where medial moraines coalesce. The edge of the medial moraine is usually well defined. In some cases, supraglacial streams located at the edge of the moraine efficiently sluice away debris delivered to them from the moraine on one side. In other cases, the debris feathers into a discontinuous cover of scattered clasts. The smallest of these clasts actually disappear into the ice as they enhance the local melt rate, creating little holes, called cryoconites, in which they are hidden from anything but a vertical view.

Significant alteration of the glacial melt pattern by the presence of medial moraine debris occurs when medial moraines widen and merge down-glacier. Quantification of this problem requires that we understand the controls on widening patterns of individual moraines. These are set by the rate of production of debris from the tributary glacier walls, and by the ablation history to which a parcel of ice is subjected below the ELA. The topology of the glacial valley network then dictates the points of addition of new moraines to the trunk glacier. In situations in which the glacial surface becomes mantled by merging medial moraines, the ablation rate of the ice may be significantly damped. The resulting mass-balance profile may promote greater extension of the glacier down-valley than the meteorological forcing alone would suggest.

The goal of this paper is first to predict the expected pattern of a solitary medial moraine's topography and debris thickness as a function of distance down-glacier from the equilibrium line. This model is then expanded to incorporate
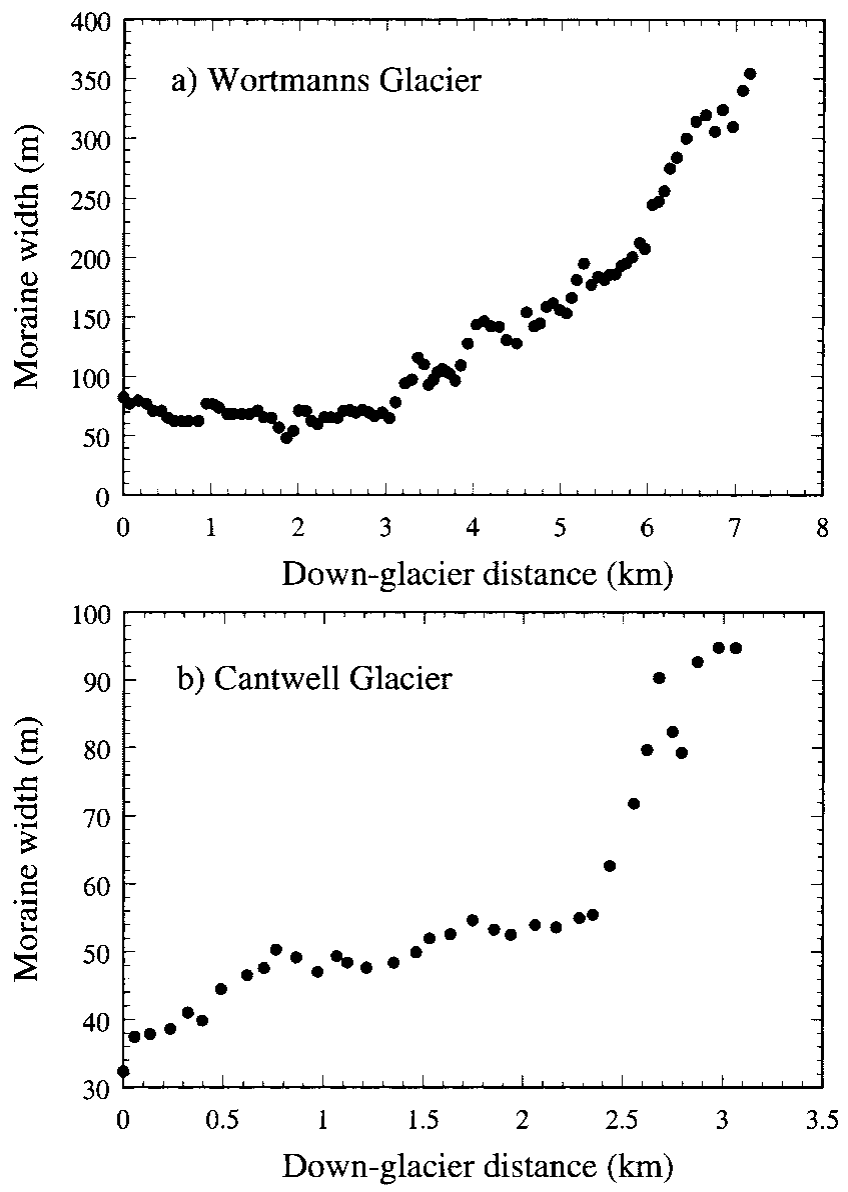

Fig. 2. Medial moraine widths, digitized from air photos, as a function of down-glacier distance for (a) Wortmanns Glacier and (b) Cantwell Glacier, Alaska. On the Wortmanns plot, zero distance corresponds to the tributary junction; on the Cantwell, it is arbitrary. The slight diminution of moraine width between $\mathrm{km} 0$ and 2 on Wortmanns Glacier is associated with ice dynamics in the region of the tributary junction. Beyond this, note the strongly non-linear growth of width with down-glacier distance.

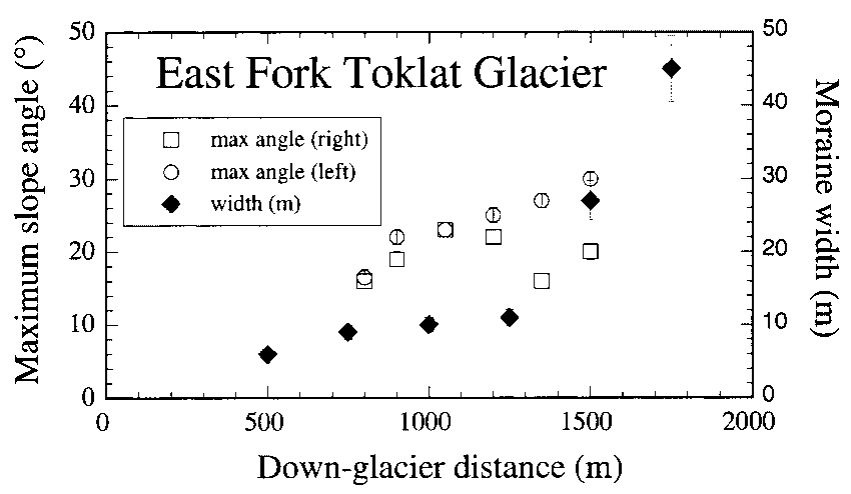

Fig. 3. Maximum slope and moraine width as functions of down-glacier position from East Fork Toklat Glacier. Maximum slopes on both sides of the moraine increase with distance down-glacier, asymptoting to roughly $30^{\circ}$. Moraine width (diamonds) increases dramatically. 
multiple merging moraines in order to assess the degree to which the meteorologically driven ablation rate is suppressed.

\section{GONCEPTUAL MODEL}

By far the most thorough and elegant conceptual picture of how medial moraines evolve is that outlined by Bozhinskiy and others (1986), who set up the problem of debris-enhanced ablation in ice. The thickness of debris on the glacier surface at a point near a medial moraine is determined by several processes, some of which add to the thickness, and some of which subtract. Debris emerges from the interior of the glacier at a rate dictated by the local ice-melt rate and by the concentration of debris in the ice being melted. Since the ice-melt rate is very sensitive to debris thickness, the presence of even a thin layer of debris subdues the melt rate (e.g. Driedger, 1981; Bozhinskiy and others, 1986; Lundstrom, 1992; Lundstrom and others, 1993). The ice surface in the zone of emerging debris therefore lowers at a slower rate than that of the adjacent, debris-free surface, and relief of the moraine feature increases. This generates surface slopes that in turn promote the dispersal of the debris. Once on the surface, debris may be transported by a variety of surface processes akin to those operating on regolith-mantled hillslopes. On average, debris is moved down local slopes. As the increase in relief is accompanied by the increase in local slopes, the moraine widens as it evolves.

In order to cast this word picture of medial moraine evolution quantitatively, the meteorologically driven spatial pattern of bare-ice melt rate, and the dependence of melt rate on debris thickness, must both be specified. The melt-rate history of a parcel of ice is dictated by this spatial melt pattern and the velocity of the ice through this pattern. Finally, a physically based model for how the debris is redistributed on the ice surface is needed. The relevant equations are presented first, from which first-order analytical results can be derived using a set of simplifying assumptions. Numerical models of medial moraine growth are then presented. The results from these models guide a scaling of moraine width vs distance down-glacier which allows assessment of the meteorological, topological and erosional conditions under which debrismantling of the ice surface will significantly reduce the mean ablation rate.

\section{ANALYTICAL MODEL}

Conservation of debris at the ice surface results in an expression for the rate of change of debris thickness, $H$, with time, $t$ :

$$
\frac{\partial H}{\partial t}=-\frac{1}{1-p}\left(b c-\frac{\partial Q_{x}}{\partial x}-\frac{\partial Q_{y}}{\partial y}\right)
$$

where $p$ is the porosity of the morainal debris, $c$ is local volumetric debris concentration $\left(L^{3} / L^{3}\right)$ in the emerging ice, $b$ is the local melt rate of the ice $(L / T), Q$ is the specific volumetric flux of debris per unit length of slope $\left(L^{2} / T\right)$ due to surface processes, $x$ is the down-glacier dimension and $y$ is the cross-glacier dimension (Fig. 4). The first term on the righthand side of the equation represents the source of debris generated by local melting of ice, while the second and third terms represent net accumulation or loss of debris by divergence of horizontal flux of debris.

The melt rate is dependent both upon the local meteorological forcing and upon the local debris thickness. Ignoring very thin $(<2 \mathrm{~mm})$ debris mantles, the dependence upon
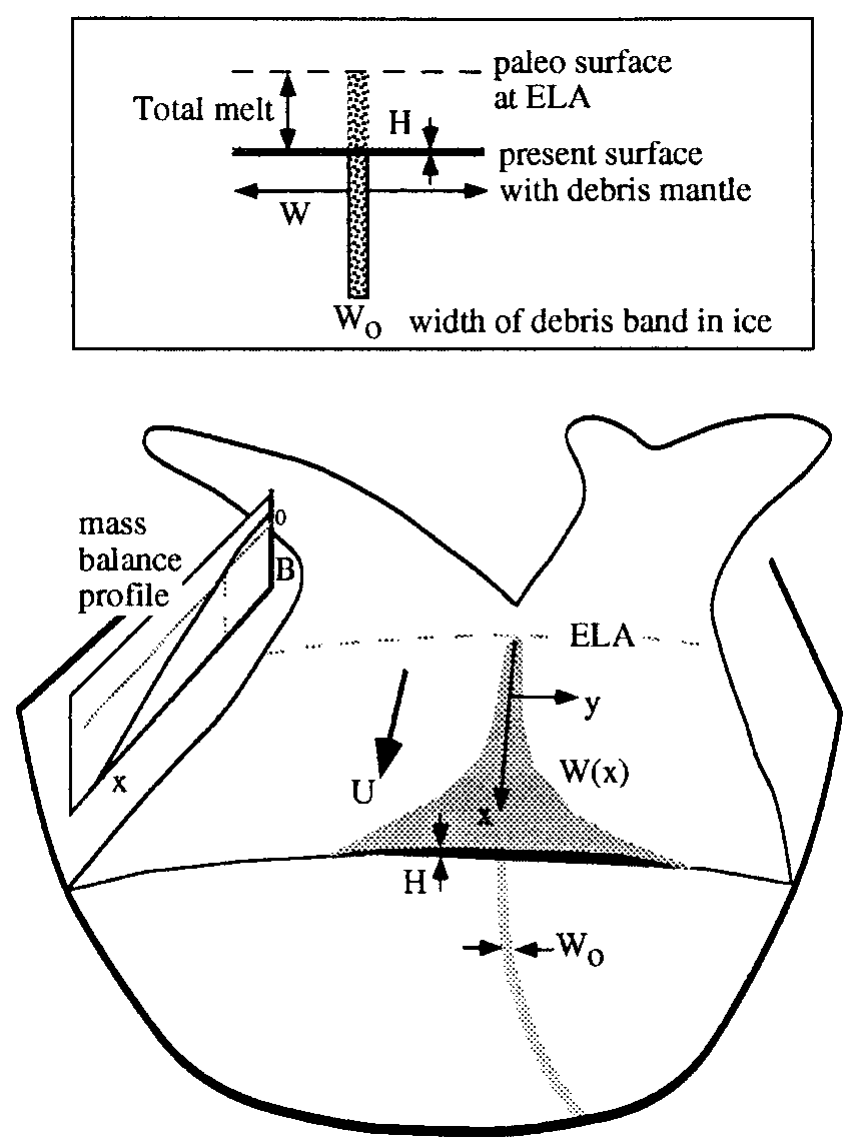

Fig. 4. Schematic diagram of medial moraine and its outcrop as
it emerges below the ELA, showing down-ice growth in moraine
width as debris is progressively exhumed by the translation
through the negative portion of the mass-balance profile, B $(x)$
(inset on left side). Coordinate system for analytical model and
numerical simulations is shown with x down-ice and y cross-
ice. Septum of debris-rich ice with original width $W_{0}$ shown
at depth, separating clean ice masses originating from the two
tributaries. Top panel is a cartoon showing conservation of
debris in a moving cross-section of ice. If the morainal debris
is uniformly thick, H, then the product WH must equal the
product of the original width $W_{0}$, the debris concentration,
and the total melt since passage past the ELA.

debris thickness may be cast as an exponentially decaying function:

$$
b=b_{0} \exp \left(-H / H_{*}\right),
$$

where $b_{0}$ is the melt rate on bare ice (taken here to be positive), and $H_{*}$ is a length scale reflecting the thickness of debris at which the melt rate is $1 / e$ of the bare-ice rate. In Figure 5, the data assembled by Lundstrom (1992) are replotted, along with a best fit (minimizing the square of the misfit between data and model) using Equation (2). The thickness scale $H_{*}$ is roughly $10 \mathrm{~cm}$. In general, $b_{0}$ will depend upon position on the glacier surface. It is assumed in the following models that the bare-ice melt rate depends only upon down-glacier distance, $x$.

Once debris emerges at the surface, it spreads laterally. This lateral movement of clasts must be cast formally as a volumetric discharge of morainal debris, $Q\left(L^{3} / L T\right)$. In general, this discharge ought to depend upon both the local slope and the thickness of the debris cover. There ought to be no flux if the thickness of debris is zero. Field observations on numerous temperate Alaskan glaciers suggest that when the debris cover on the ice surface is thin, roughly one clast 


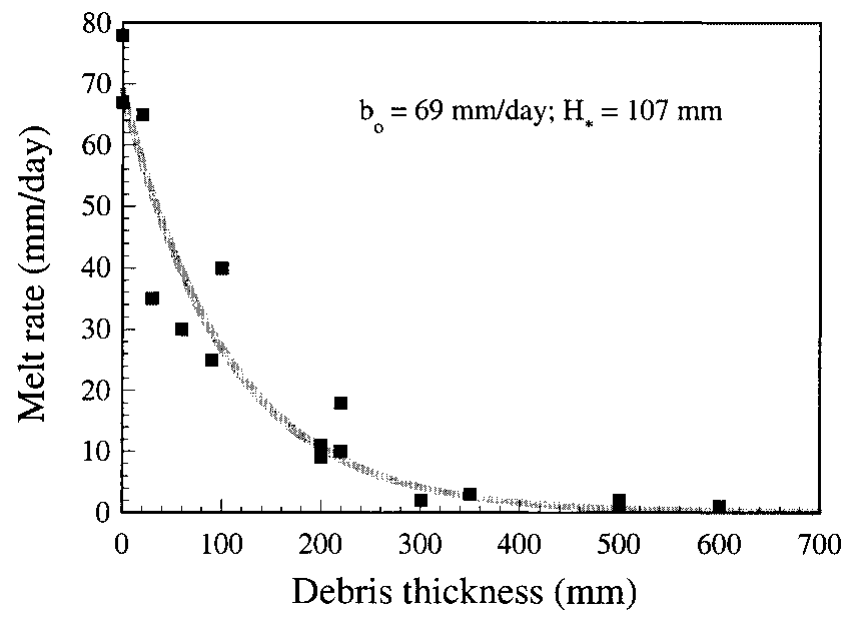

Fig. 5. Ablation-rate dependence on debris-cover thickness, replotted from Lundstrom and others (1993). Curve is best fit to an exponentially decaying function (Equation (2)), with bare-ice melt rate, $b_{0}$, and length scale for decay to 1/e of bareice value, $H_{*}$, shown.

diameter, debris moves by the development and collapse of small-scale ice tables. The underlying ice is protected from melt, resulting in growth of the table, which eventually sheds its clast as the clast slips to one side or another. Rarely are pillars much greater in height than the clast diameter. Upon toppling from a pillar, the clast may either simply halt at the base of the pillar, or skitter slightly downhill before coming to rest. This leads to the more-or-less random motion of clasts, with a slight propensity for motion downhill (Fig. 6). This description of the grain-scale process may be cast in a continuum sense using:

$$
Q_{y}=\frac{C V \delta}{\tau},
$$

where $C$ is the number of clasts per unit area of ice surface, $V$ is the volume of a single clast, $\delta$ is the mean step length a clast makes and $\tau$ is the frequency with which steps are taken (Fig. 6).

The areal concentration of clasts, $C$, is related to the mean local thickness of debris through $H=C D^{3}$, where $D$ is a characteristic clast diameter. The magnitude of the step, $\delta$, is simply the clast diameter if the clast merely falls to the base of the pillar. To this we must add any additional motion the clast makes once it has fallen. It is here that the dependence on the local slope, $\alpha$, arises. Averaging over all azimuths of topple, $\theta(\theta=0$ being downhill $)$, the mean step length becomes $D \beta \tan \alpha$, where $\beta$ is a factor reflecting the additional distance, in numbers of clast diameters, that the clast travels straight down the fall line (see Fig. 6). The frequency of steps is set by the time necessary to grow a pedestal of height sufficient to topple the clast. If, as is reasonable, this critical pedestal height, $L$, scales with the clast diameter (say $L=\gamma D$ ), the time-scale becomes this pedestal height divided by the differential ablation rate between ice directly underlying the clast and bare ice adjacent to the pedestal:

$$
\tau=\frac{L}{\Delta b}=\frac{\gamma D}{b_{0}-b(D)}=\frac{\gamma D}{b_{0}-b_{0} \exp \left(-D / H_{*}\right)} .
$$

Replacing $\tan \alpha$ with the local slope, $\nabla z$, in the expression for the mean step length, the debris discharge may now be written

$$
Q=-H \frac{\beta}{\gamma} b_{0}\left[1-\exp \left(-D / H_{*}\right)\right] \nabla z
$$

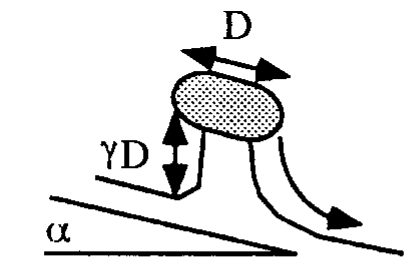

propensity for downslope motion

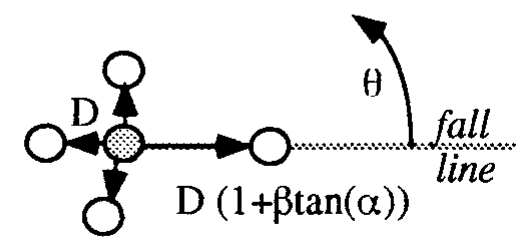

Fig. 6. Schematic of debris motion on the ice surface. Clasts of diameter $D$ topple from the tops of ice pedestals (top diagram) in any direction. Once they tumble to the bare-ice surface, they skitter preferentially downslope (bottom diagram), resulting in a net motion downhill.

As expected, the flux is dependent upon both the local thickness of debris, $H$, and the local slope. The only unknowns are the factors $\gamma$ and $\beta$, which scale the height of the pedestal and the azimuthal asymmetry of the step lengths, respectively.

Thicker layers of debris can be moved about by other processes. These include solifluction-like movement, in which a velocity profile within the debris sets the local fluxes, and landslides down very steep bare-ice surfaces. For each of these processes, the functional form of the flux equation would differ from Equation (5). As field observations of solitary moraines, up-valley of coalescence with other medial moraines, suggest that the dominant process there is that associated with clast-by-clast motion of sparse debris, Equation (5) is employed as the relevant flux rule.

Returning to the mass-balance Equation (1), the substitution of rules for debris input from melting (Equation (2)) and for debris movement (Equation (5)) results in a non-linear diffusion equation with a spatially variable source term. Assuming that the local topographic gradient is largely cross-glacier, i.e. that $\nabla z=\partial z / \partial y$, this equation becomes:

$$
\begin{gathered}
\frac{\partial H}{\partial t}=\frac{c b_{0} \exp \left(-H / H_{*}\right)}{(1-p)}+\left\{\frac{\beta b_{0}\left[1-\exp \left(-D / H_{*}\right)\right]}{\gamma(1-p)}\right. \\
\left.\left(H \frac{\partial^{2} z}{\partial y^{2}}+\frac{\partial H}{\partial y} \frac{\partial z}{\partial y}\right)\right\} .
\end{gathered}
$$

For situations in which the debris cover is nearly uniform, the term containing the gradient in $H$ can be neglected, and this becomes a diffusion equation for debris thickness, with an effective diffusivity, $\kappa$, of

$$
\frac{H \beta b_{0}\left[1-\exp \left(-D / H_{*}\right)\right]}{\gamma(1-p)}
$$

Given that the source of debris is limited to the edges of tributary glaciers, the debris concentration, $c$, in the emerging ice is likely to be a strong function of cross-glacier distance, $y$. In the calculations hereafter, it is assumed for simplicity that the debris concentration in the emerging ice is uniform within $\left[-W_{0} / 2, W_{0} / 2\right]$ and is 0 outside of this band (Fig. 4). While the conditions that set this concentration are treated in a subsequent section, it should be noted here that the specification of 
the debris field $c(y)$ will depend strongly upon the type of glacier, the source of debris, the potential folding of this debris septum englacially (e.g. Hambrey and others, 1999) and so on. The physics once the debris has emerged ought to be the same in all cases.

Given these assumptions, the expected behavior of the medial moraine can be assessed for some simple situations. If the debris achieves a relatively uniform thickness, say $H_{\mathrm{ss}}$, over the moraine surface, meaning that the term containing the gradient in $H$ may safely be ignored, and that this debris thickness does not change significantly through time, Equation (6) can be simplified to obtain the expected crossglacier curvature:

$$
\frac{\partial^{2} z}{\partial y^{2}}=\frac{-\gamma c \exp \left(-H_{\mathrm{ss}} / H_{*}\right)}{H_{\mathrm{ss}} \beta\left[1-\exp \left(-H_{\mathrm{ss}} / H_{*}\right)\right]} .
$$

This predicts two forms, one appropriate over ice containing debris, the other over debris-free ice (Fig. 7). Directly above the subsurface debris band (where $c=c_{0}$ ), the curvature is constant and negative, implying that the top of the moraine should be parabolic in shape. In this region, therefore, this result is perfectly analogous to G. K. Gilbert's argument for the evolution of convex hilltops (Gilbert, 1909); regolith production by weathering is analogous to ablation-induced emergence of debris, and regolith creep is analogous to the topple-walk mechanism. The slope must increase with distance from the moraine crest to accommodate the increase in discharge of debris required to generate a steady, uniform thickness of debris.

Outside of the region underlain by the debris band (where $c=0$ ), as long as the surface debris remains uniformly thick, the curvature must be zero (Equation (7) with $c=0$ ). This reflects the fact that in order to maintain a uniform surface debris layer, there can be no divergence of discharge of debris; given that debris discharge is slope-dependent (Equation (5)), there can be no change in slope. This slope is set by that at the edge of the debris band (at $\pm W_{0} / 2$ ). In other words, integrat-

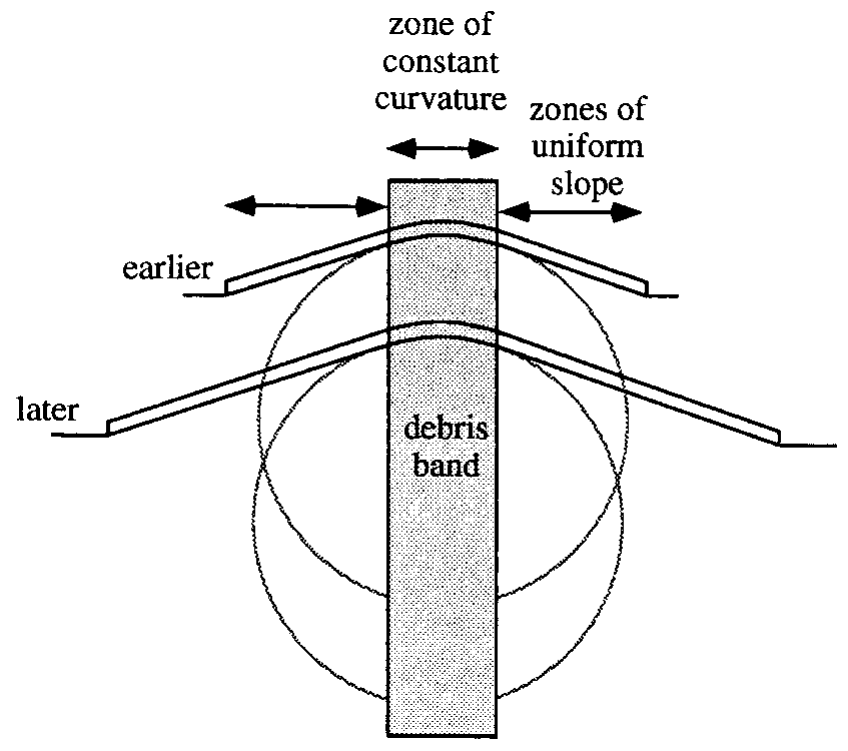

Fig. 7. Schematic diagram depicting analytical results. The moraine attains uniform curvature (tangent to a circle) over the debris source, and straight linear slopes on either side of this region. Beyond the moraine, an abrupt break in slope marks the flat bare-ice surface. Since the debris thickness remains uniform, the straight slopes must extend through time to accommodate the emergence of new debris. ing Equation (7) once and evaluating at the edge of the debris band,

$$
\left(\frac{\partial z}{\partial y}\right)_{\max }=\left(\frac{\partial z}{\partial y}\right)_{W_{0} / 2}=-\frac{\gamma c_{0} \exp \left(-H_{\mathrm{ss}} / H_{*}\right)}{H_{\mathrm{ss}} \beta\left[1-\exp \left(-D / H_{*}\right)\right]} \frac{W_{0}}{2} .
$$

From the above argument, as long as the width of the debris-rich ice septum, $W_{0}$, does not change significantly down-glacier, the maximum surface slope of the emerging moraine should not change as the moraine widens.

Using the same set of assumptions, the moraine width, $W$, should grow linearly with the time, $T$, once debris begins to emerge on the ice surface. Conservation of debris (see Fig. 4 inset) requires that the volume of debris on the surface per unit down-glacier length of moraine, $W H_{\mathrm{ss}}$, must equal all of the material that has emerged since passage through the ELA, $b^{\prime} c_{0} W_{0} T$. Solving for the width,

$$
W=\int_{0}^{x} \frac{b^{\prime} c_{0} W_{0}}{H_{\mathrm{ss}}} \mathrm{d} t=\frac{b^{\prime} c_{0} W_{0}}{H_{\mathrm{ss}}} T .
$$

Again, here I have assumed that the debris-reduced melt rate, $b^{\prime}$, remains constant in time, in accord with the simplification that debris thickness takes on a single value, $H_{\mathrm{ss}}$, i.e. that $b^{\prime}=b_{0} \exp \left(-H_{\mathrm{ss}} / H_{*}\right)$.

Finally, the evolving moraine relief (defined as the elevational difference between the moraine crest and the adjacent bare ice) should grow linearly through time at a rate dictated by the difference between the melt rate on the uniformly mantled moraine surface and that on the adjacent bare ice:

$$
R_{\mathrm{m}}=\left(b_{0}-b^{\prime}\right) T \text {. }
$$

These results, including spatially non-uniform maximum slope, and linear increase of both width and relief with down-glacier distance, can explain neither the observation of increasing moraine slope with distance down-glacier (Fig. 3) nor that of greater-than-linear growth of moraine width with down-ice distance (Fig. 2). This mismatch between the analytic theory and the observations could reflect the breakdown of any of the assumptions made in the analysis. The debris concentration or the original width of the debris-laden ice will probably vary, due in part to stochastic processes involved in the delivery of debris to the tributary glacial margins. This effect, however, should simply introduce noise to the moraine-width pattern. Instead, the systematic variation of bare-ice ablation rate, $b_{0}$, with distance down-ice, and hence through time as a parcel of moraine is moved through this meteorologically driven melt-rate pattern, is more likely the source of systematic deviation from this linear-growth result. This problem is addressed with a simple numerical simulation of medial moraines in which some of the simplifications made in the above analysis can be relaxed.

\section{NUMERICAL RESULTS}

Two assumptions made in order to make the analytic model tractable can be relaxed with a numerical model. The assumption of steady and uniform debris cover is relaxed, and the ice-melt rate is allowed to vary through time, reflecting down-glacier translation of the ice surface into a warmer, higher-melt-rate microclimate. The melt rate is allowed to increase linearly with down-glacier distance (hence with decreasing elevation), in accord with most models of local 
mass-balance profiles below the ELA (e.g. Oerlemans and Fortuin, 1992; Booth and Hallet, 1993; Oerlemans and others, 1998). In addition, the surface ice velocity is allowed to be a specified function of down-glacier distance. These two factors allow the bare-ice melt rate to vary in a more complex way as an ice parcel moves down-glacier.

The problem is treated as one-dimensional, reflecting the argument that gradients and curvature of the ice surface in the down-glacier direction are small relative to those in the cross-glacier direction. The down-glacier variation in the melt rate is accounted for by following a cross-valley slab of ice, and by both dictating the down-glacier melt-rate pattern and specifying the down-glacier surface speed history for the ice parcel. The equations for continuity of debris, for ice melt and for debris movement are cast into finite-difference form, with a cross-glacier node spacing of $2 \mathrm{~m}$. The 1D code utilizes a staggered grid in which debris thickness and melt rate are associated with cell centers. Fluxes are calculated at the edges of the cells using slopes calculated from differences in the elevations of the adjacent cell centres, and the debris concentration of the upslope cell. Debris is conserved in all model runs.

In the first model run (Fig. 8), local bare-ice melt rate is held constant at $0.4 \mathrm{~m} \mathrm{a}^{-1}$, through the 150 year run, to confirm the results of the analytical calculations. The parameter scaling the clast step length, $\beta$, is set to 3 , that dictating the critical pedestal height, $\gamma$, to 1 , the porosity to 0.35 , and the ablation length scale $H_{*}$ to $0.11 \mathrm{~m}$. The volumetric debris concentration, $c_{0}$, is set to $0.01 \mathrm{~m}^{3} \mathrm{~m}^{-3}$ within a $10 \mathrm{~m}$ wide zone centered on $0\left(W_{0}=10 \mathrm{~m}\right)$, and to zero outside of this. In Figure 8a, the top flat line is the initial condition, and the bottom bold line is the final 150 year cross-profile of glacier surface including the medial moraine. The even spacing of lines outside of the moraine illustrates steady melt rate of bare ice. The surface debris evolves into a layer of nearly uniform thickness that widens through time near the debris source at the moraine center, and feathers to zero at the edges. Note that the uniform thickness of the debris near the debris source is roughly half of the length scale $H_{*}$ at which melt rate is reduced by $1 / e$ of that for bare ice. Given that the moraine achieves a steady debris thickness, and the emergence of debris is set by the steady melt rate, the volumetric flux of debris to the glacier surface becomes steady, and the moraine widens linearly with time (Fig. 8d). The moraine crest, over the finite debris source $[-5,5]$, attains the parabolic profile expected from the analytical results, while the side-slopes outside of the debris source are linear, again as expected from the analytic solution (cf. Figs 7 and 8a). A subtlety not captured by the analytic model is the spikes of higher debris thickness at the edges of the moraine, associated with the abrupt change in slope at the join with bare ice. This causes a strong local divergence of debris discharge, the location of which moves outward as the moraine widens. The cross-glacier melt-rate pattern (Fig. 8c) mimics the debris-thickness pattern. As in the analytical results, the moraine grows linearly in width (Fig. 8d; discretized nature of the plot is an artifact of the calculation). The maximum slope (Fig. 8e) grows to a maximum of roughly $30^{\circ}$ within 25 years, at which it is maintained thereafter. Relief (Fig. 8f) grows linearly with time.

A second run demonstrates how this simple system is altered if the moraine translates into warmer microclimate through time, as would be expected on a real glacier. The results are shown in Figure 9 for a run in which the horizontal gradient in bare-ice melt rate was dictated to be $4 \mathrm{~m} \mathrm{a}^{-1} \mathrm{~km}^{-1}$, and the surface ice speed was set to $40 \mathrm{~m} \mathrm{a}^{-1}$ at the ELA, tapering to 0 at the terminus $4 \mathrm{~km}$ down-glacier from the ELA. All other parameters are held the same between runs. The result is that the bare-ice melt rate increases through the
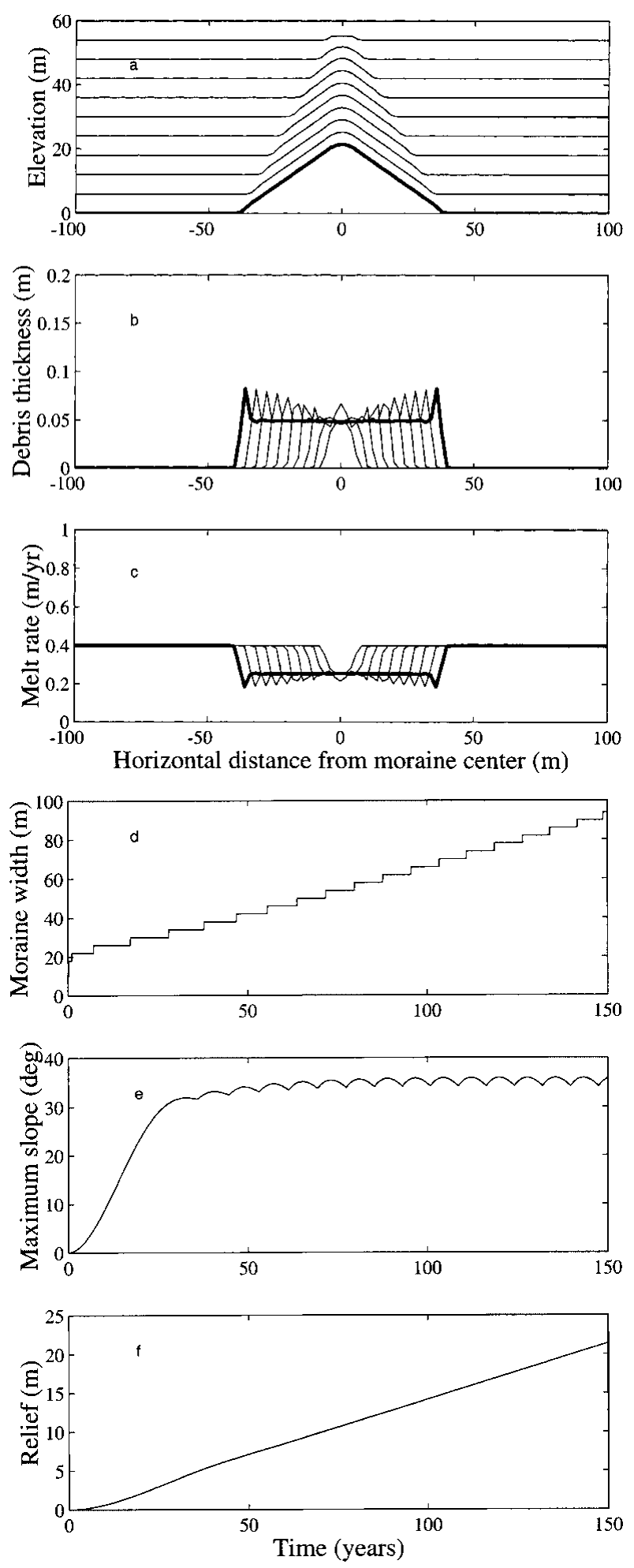

Fig. 8 . Numerical results of 150 year model run in which bare-ice melt rate is taken to be steady at $0.4 \mathrm{~m} \mathrm{a}^{-1}$. Fifteen-year snapshots of (a) topographic profiles of the moraine, $(b)$ debris thickness and (c) melt-rate pattern. In (a), top line is initial condition, bottom bold line is final 150 year cross-profile of glacier surface including moraine. In (b) the earliest snapshot of debris cover is the narrowest, showing finite debris only over the $10 \mathrm{~m}$ wide band of debris-rich ice. Final profile is bold. Evolution of width $(d)$ is linear with time, maximum slope (e) achieves a maximum of roughly $35^{\circ}$, and relief $(f)$ increases linearly. 
model run, as reflected in the increasing vertical spacing between the profiles shown in Figure 9a. Again the debris thickness attains a uniform steady-state thickness (Fig. 9b). While the cross-sectional form of the moraine appears to be
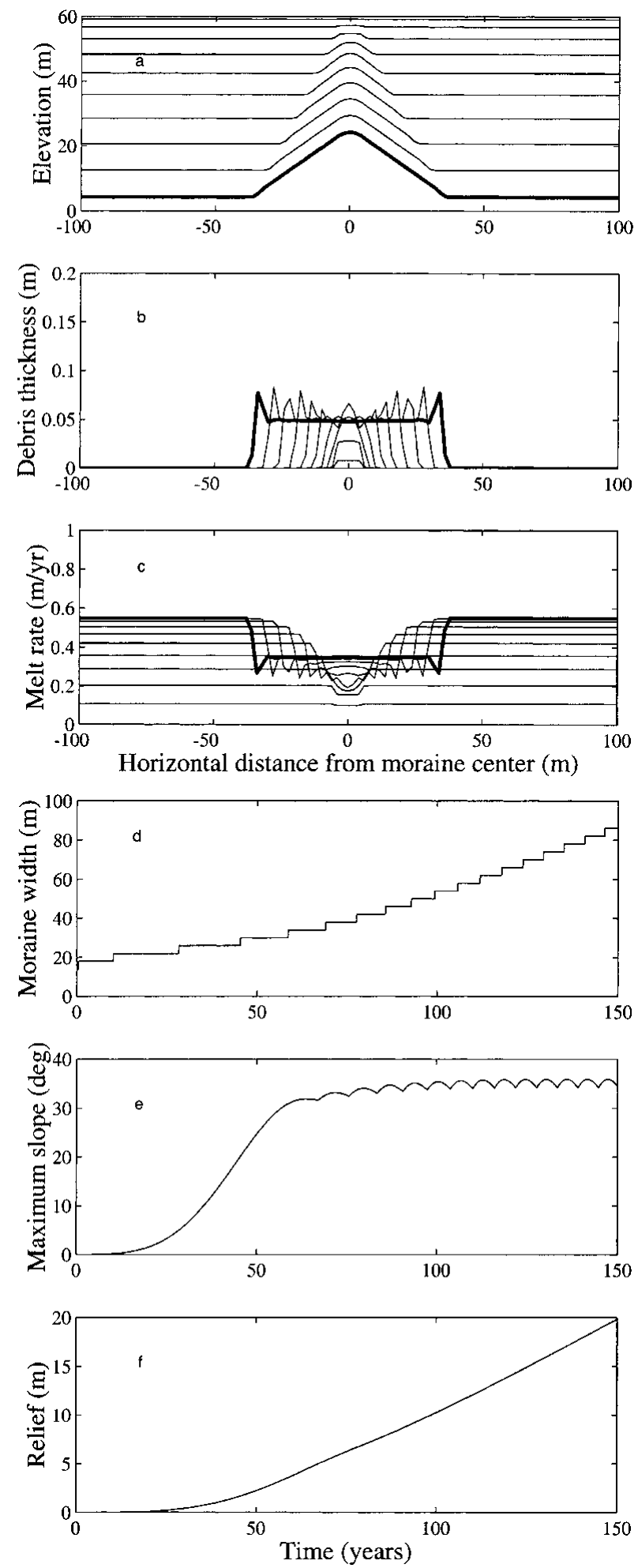

Fig. 9. Results of a run that differs from that shown in Figure 8 only in that the bare-ice melt rate is allowed to evolve as the ice translates down-valley into a warmer microclimate. This is reflected in the increasing distance between bare-ice surfaces outside of the moraine in (a). Debris-thickness pattern ( $b$ ) and melt-rate reduction pattern (c) are similar to those in Figure 8. In contrast to the simulation shown in Figure 8, the moraine width grows non-linearly with time $(d)$. As in the steady scenario, maximum surface slope increases through time as well (e), stabilizing at $35^{\circ}$. The moraine relief $(f)$ grows increasingly rapidly as it is subjected to increasing bare-ice melt rates. similar, parabolic on top and straight-sided beyond the debris source, the more obvious differences lie in the temporal evolution of the moraine width and relief (Fig. 9d and f). The moraine grows in both width and height at an increasing rate, reflecting the increasing bare-ice melt rate.

In a final simulation, the effects of merging moraines are highlighted (Fig. 10a). Two debris septa are inserted in the model, the second (right) one as wide as, but having half the debris concentration of, the center one. Both moraines grow at the expected rate until their edges begin to interact. The debris arriving at the base of the moraine slopes can no longer move onto bare ice, and begins to accumulate in the positive-curvature trough between moraines. The debris there rapidly attains a thickness greater than that over any other part of the ice surface (Fig. 10b), greatly damping the melt rate (Fig. 10c). This in turn allows the local relief (trough-to-crest elevation difference) to decline, such that by the end of the simulation the smaller of the moraines is in the process of being subsumed in the larger (Fig. 10a).

While the topography of the moraine is interesting, it is the reduction in melt rate that affects the mass-balance profile and hence the expected extent of a glacier. Figure 11 depicts the reduction in the local (cross-valley averaged) melt rate below that expected from the bare-ice melt rate at each down-glacier position. At the furthest down-valley position in this simulation, the melt rate is reduced by $>10 \%$. More dramatic reduction is allowed by a larger number of moraines, and greater distances down-ice, allowing thicker debris cover in the troughs.
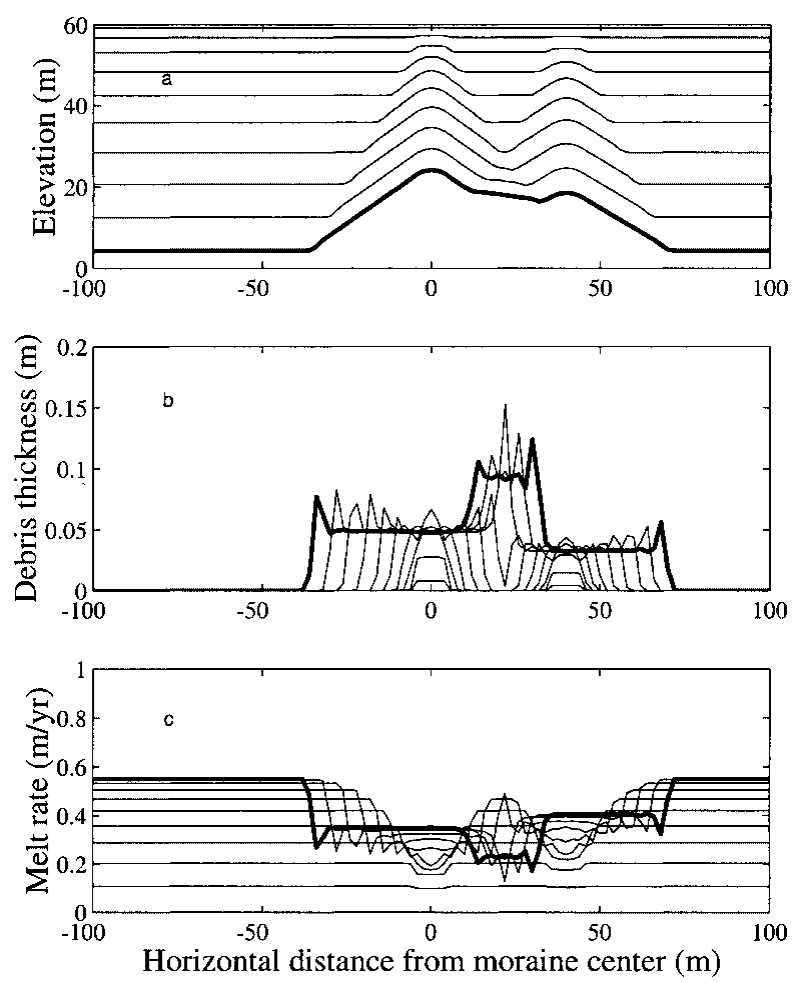

Fig. 10. Simulation illustrating amalgamation of two medial moraines. Same parameters as in runs depicted in Figures 8 and 9, except that a second moraine is introduced at $+40 \mathrm{~m}$. Width of the debris band is again $10 \mathrm{~m}$, but initial concentration of the second band is half that of the dominant moraine. (a) Evolving topography showing merging of moraines. (b) Debris thickness; note the significant accumulation of debris in the trough between moraines once they begin to coalesce. (c) Associated reduction in the melt rate. 


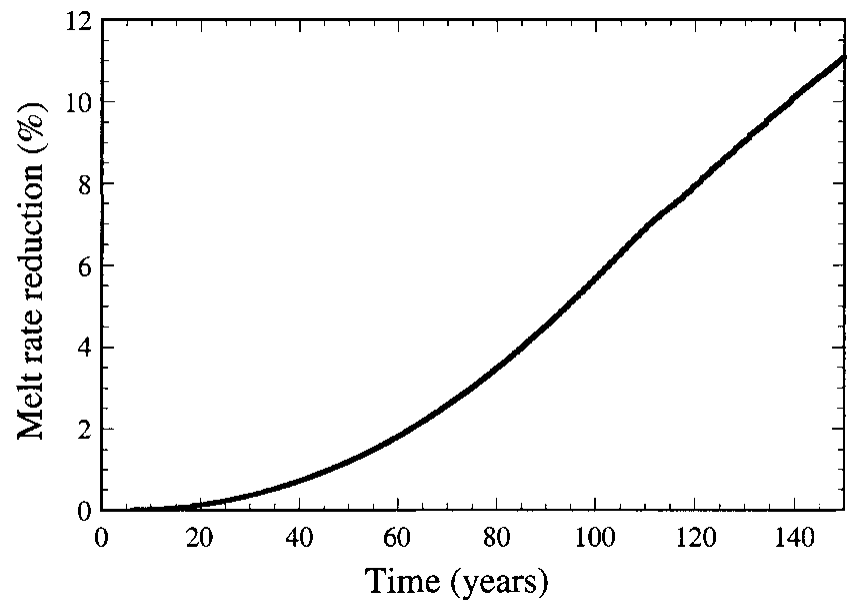

Fig. 11. Reduction of melt with distance down-glacier due to growing effects of emergent debris, from simulation shown in Figure 10. By the end of this simulation, the local melt rate has been reduced by $>10 \%$ by the presence of the debris on the ice surface (see Fig. 10c).

\section{GONTROLS ON DEBRIS CONGENTRATION IN IGE}

Thus far the debris concentration in the glacial ice has simply been specified. Closure of the problem requires an expression for the controls on the debris concentration. The debris emerging at the medial moraine is derived largely from sources on the walls of each of the two tributaries that comprise the adjacent streams of ice (Fig. 12). The concentration of debris in the ice as it passes into the tributary junction should therefore reflect the lengths of these tributaries, the erosion rates of the walls and the heights of the walls. Allowing for some contribution from subglacial erosion, and assuming that all debris being supplied to the glacier margin is being transported (i.e. there is no long-term storage of debris against the tributary glacier), the flux of debris at the confluence is accomplished by motion of ice at a rate $U$ with a finite debris concentration, $c_{0}$ :

$$
\begin{aligned}
& c_{0} W_{0}(\xi G) U= \\
& \xi_{\mathrm{w}_{1}} \Delta_{1}\left(R_{\mathrm{v}}-G\right)_{1}+\xi_{\mathrm{w}_{2}} \Delta_{2}\left(R_{\mathrm{v}}-G\right)_{2} \\
& +\xi_{\mathrm{g}_{1}} \Delta_{1} G_{1}+\xi_{\mathrm{g}_{2}} \Delta_{2} G_{2},
\end{aligned}
$$

where $\epsilon_{\mathrm{w}}$ is the erosion rate of the wall, $\epsilon_{\mathrm{g}}$ is subglacial morainal debris production, $R_{\mathrm{v}}$ is the glacial bed-to-ridge top relief, $G$ is the glacier thickness, $\Lambda$ is the length of a tributary, $\xi$ is the fraction of the glacial depth occupied by the medial moraine septum [0,1], and the subscripts 1 and 2 refer to the two tributaries (Fig. 12). Solving for the product $c_{0} W_{0}$, which may be called the effective width of the moraine septum, yields:

$$
\begin{aligned}
c_{0} W_{0} & =\left(\frac{\left(R_{\mathrm{v}}-G\right)_{1}}{\xi G} \epsilon_{\mathrm{w}_{1}} \frac{\Delta_{1}}{U}\right)+\left(\frac{\left(R_{\mathrm{v}}-G\right)_{2}}{\xi G} \epsilon_{\mathrm{w}_{2}} \frac{\Delta_{2}}{U}\right) \\
& +\left(\frac{G_{1}}{\xi G} \epsilon_{\mathrm{g}_{1}} \frac{\Delta_{1}}{U}\right)+\left(\frac{G_{2}}{\xi G} \epsilon_{\mathrm{g}_{2}} \frac{\Delta_{2}}{U}\right) .
\end{aligned}
$$

Here the first two terms on the righthand side represent contributions from supraglacial sources, while the last two reflect subglacial contributions. In general, the angularity of debris in the medial moraines on which I focus reflects the large role played by supraglacial sources, and we can safely ignore the second pair of terms. In the valley-wall terms, the inverse of the first ratio, $G /\left(R_{\mathrm{v}}-G\right)$, is a

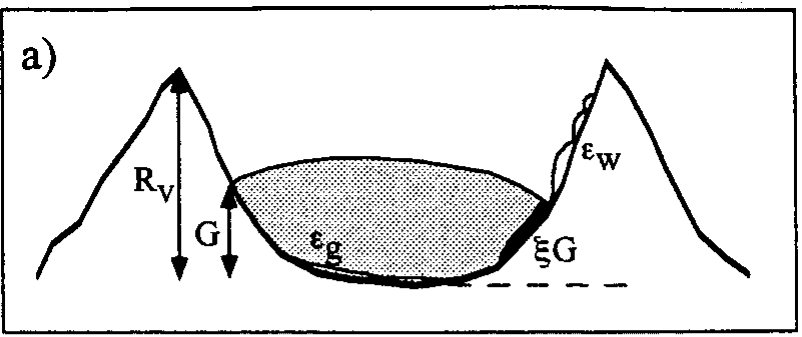

b)
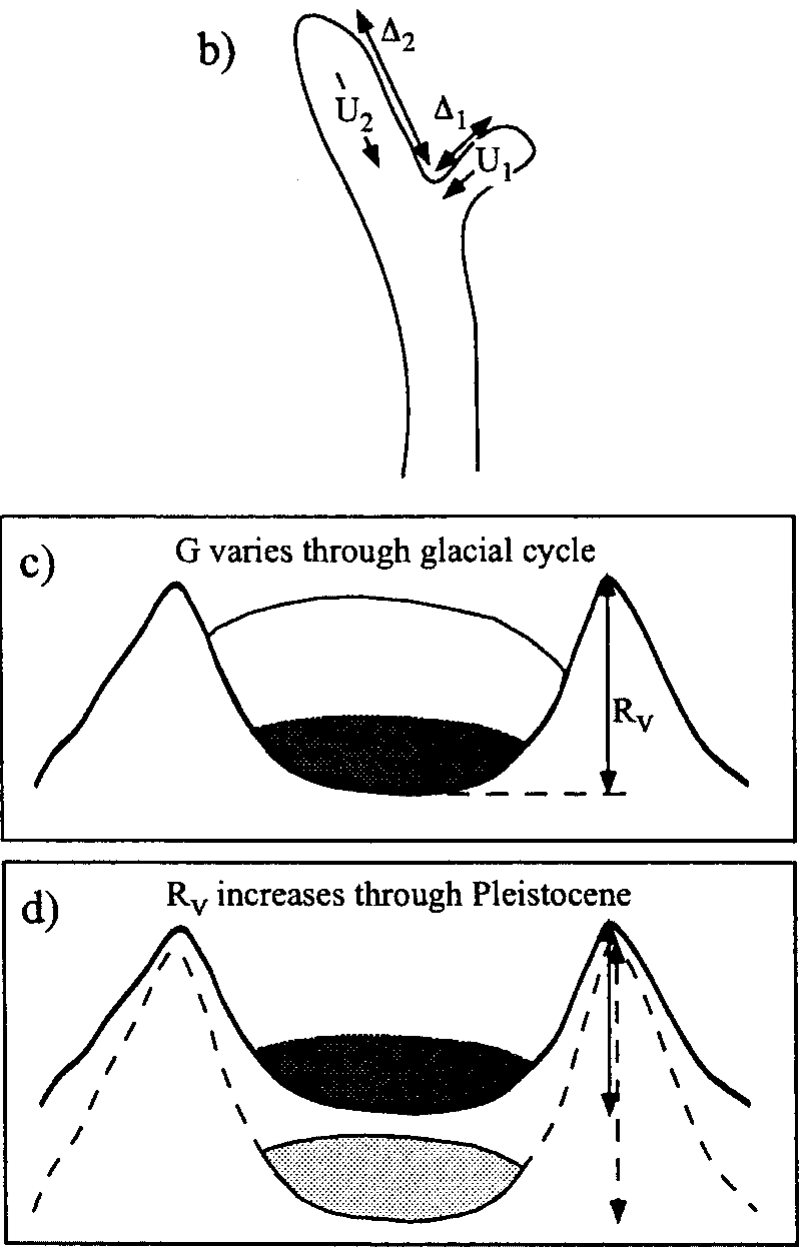

Fig. 12. Schematic cross-section ( a) and map view (b) of glacier with tributary junction, showing sources of debris from tributary junction walls. The source strength of the debris delivered to the edges of the tributaries is set by the erosion rate of the walls, $\epsilon_{\mathrm{w}}$, and their vertical length. This is in turn set by the difference between the ridge-valley floor bedrock relief, $R_{\mathrm{v}}$, and the glacial depth, $G$. Over individual glacial cycles (c), during which the ridge relief does not vary greatly, the modulation of the glacial thickness will strongly influence the wall length and hence the source of debris. Over long time-scales (d), ridge-valley floor relief can increase, lengthening the valley walls above the glacier, promoting a stronger debris source.

"swamping factor" denoting the degree to which the valley is filled with ice. As this ratio increases, the debris source from the valley walls is shut off as the valley becomes swamped by ice. The second ratio, $\Delta / U$, is the time-scale for the translation of ice past the eroding wall. The strength of the debris source is therefore set by the valley-wall erosion rate, the height of the valley walls above the glacier surface and the time spent by a parcel of ice in translating past the wall. Given this formulation, one could carry out the numerical simulations of moraine evolution for particular geological and topological situations. 


\section{DISGUSSION}

The above analysis has not treated the effects of ice dynamics on the moraine evolution: the shear-thinning of the internal debris band, the potential for folding of debris-rich septa and down-glacier emergence of these folds (e.g. Hambrey and others, 1999), and the potential for the widening of the band associated with (negative) horizontal gradients in surface velocity. Any conversion of the down-valley velocity gradient in the ablation area to a lateral velocity gradient of the opposite sign will indeed result in the widening of both the topographical feature of the moraine itself and the debrisrich ice band at depth. These ice dynamics have not been documented on the glaciers on which the medial moraines discussed herein occur. While for completeness the effects of lateral ice strain should be included, consider for the moment the debris-cover thickness as a strain marker. If lateral extensional strain of the glacial surface of the scale necessary to explain the widening of medial moraines were to occur, one would expect to witness significant decrease in the debris-cover thickness with distance down-ice on the straight flanks of moraines. On the contrary, the debris is very consistently one clast thick. This is far better explained by appeal to the lateral spreading of debris by hillslope processes described above, accommodating the arrival of new debris at the surface within the debris-rich septum.

\section{Scaling of moraine widths and their impact on the glacier melt-rate pattern}

Given the numerical results and their implication that the down-valley pattern of bare-ice melt rate is important, an analytic expression is derived here for medial moraine width as a function of down-glacier distance that better reflects the meteorologically driven mass balance. This allows a first-order scaling of the controls on the degree to which the mean melt-rate pattern of a glacier is affected by debris cover. Converting the temporal integral in Equation (9) to one of space through $\mathrm{d} t=\mathrm{d} x / U$, and again assuming that the debris thickness may be characterized by the steady-state thickness scale $H_{\mathrm{ss}}\left(\sim H_{*}\right)$ :

$$
W=\int_{0}^{x} \frac{b^{\prime} c_{0} W_{0}}{H_{\mathrm{ss}}} \mathrm{d} t=\int_{0}^{x} \frac{b^{\prime}(x) c_{0} W_{0}}{U(x) H_{\mathrm{ss}}} \mathrm{d} x .
$$

Consider a reach of glacier in which the surface velocity may be taken to be slowly varying relative to the debris-reduced melt rate, $b^{\prime}$, and assume that the bare-ice melt rate increases linearly with distance down-glacier, i.e.

$$
b^{\prime}=b_{0}(x) \exp \left(-H_{\mathrm{ss}} / H_{*}\right)=\eta x \exp \left(-H_{\mathrm{ss}} / H_{*}\right),
$$

where $\eta$ is the gradient in melt rate with horizontal distance below the ELA. The dependence of medial moraine width on distance below the ELA becomes:

$$
\frac{W=\eta \exp \left(-H_{\mathrm{ss}} / H_{*}\right) X^{2} c_{0} W_{0}}{2\langle U\rangle H_{\mathrm{ss}}}
$$

Here $\langle U\rangle$ is the mean surface ice speed between the ELA and the point $\mathrm{X}$. Note the dependence of moraine width on distance from the ELA is non-linear, going as the square of the distance from the ELA. This is in accord with the moraine-width profiles shown in Figures 2 and 3.

Combining Equation (15) with the expression for the effective debris width, $W_{0}$, responsible for any particular moraine (Equation (12)) yields an equation for the fraction of the glacier width covered by morainal debris from each of $N$ moraines:

$$
\begin{aligned}
& \frac{W}{W_{\mathrm{g}}}=\frac{\eta \exp \left(-H_{\mathrm{sS}} / H_{*}\right)}{2 W_{\mathrm{g}}\langle U\rangle H_{\mathrm{Ss}}} \sum_{i=1}^{N} X_{i}^{2} \\
& {\left[\left(\frac{\left(R_{\mathrm{v}}-G\right)_{i_{1}}}{\xi G} \epsilon_{\mathrm{w}_{i_{1}}} \frac{\Delta_{i_{1}}}{U}\right)+\left(\frac{\left(R_{\mathrm{v}}-G\right)_{i_{2}}}{\xi G} \epsilon_{\mathrm{w}_{i_{2}}} \frac{\Delta_{i_{2}}}{U}\right)\right],}
\end{aligned}
$$

where $W_{\mathrm{g}}$ is the full glacial width, and the index, $i$, corresponds to a particular tributary confluence and hence a particular medial moraine among the total, $N$. Here the relatively minor contributions from subglacial debris (the second pair of terms in Equation (12)) have been ignored. As the ratio of $W / W_{\mathrm{g}}$ approaches 1.0, the importance of debris cover in limiting the mean ablation rate at the glacier surface increases.

This scaling suggests that the likelihood of significant damping of the mean melt rate depends on several geometrical characteristics of the basin: the number of tributaries, $N$, their lengths, $\Lambda$, and the distances of their confluence from the terminus, $X$. In addition, several climatological factors come into play. The gradient of the bare-ice melt rate, $\eta$, with down-glacier distance is set to first order by the altitudinal gradient of temperature (the lapse rate) and the slope of the valley. The speed, $U$, at which the ice translates past the wall debris sources in each of the tributaries will vary with ice thickness and hence with time within the glacial cycle. However, the faster the glacier surface moves below the ELA, scaled by $\langle U\rangle$, the less time the moraines have to widen before they reach the terminus. Finally, the swamping factor $G /\left(R_{\mathrm{v}}-G\right)$ ought to modulate the debris source strength through a glacial cycle (Fig. 12c). Interestingly, the swamping factor should decrease as glacial erosion increases the valley relief, $R_{\mathrm{v}}$, through the Pleistocene Epoch (Fig. 12d). This exposes more non-glacial valley-wall area over long time-scales, creating a stronger source of debris. Acting alone, this effect would promote longer glaciers for the same meteorological forcing over long time-scales.

\section{GONGLUSIONS AND IMPLICATIONS}

The intent of this paper was to shed light on the linkages among processes that affect the evolution of medial moraines, to explore the conditions leading to the feedbacks between moraine cover and glacial extent, and to promote the careful measurement of the geometrical characteristics that can be used to constrain such a model. The general cross-sectional shape of medial moraines, and their downglacier variations in width and relief, can be explained using the model described here. While the nature of the damping of the melt rate by debris thickness is well characterized by past work, the mechanisms by which morainal debris moves across the ice surface have received less attention. The table-topple mechanism observed to be operating obeys our intuition in that the discharge of debris is a function of both the local slope and the debris thickness. Within very wide moraines, and continuous debris cover, other mechanisms clearly operate. For example, supraglacial streams incise into the moraines, creating very steep channel-wall slopes that serve to deliver debris to the channel by mass wasting, where it is removed from the cross-section in the channel. Incorporation of these processes would tend to reduce the feedbacks discussed herein, as they remove debris from the 
morainal system that would otherwise remain in the crosssection to reduce melt rate.

Not treated is the potentially complex evolution of the debris-rich ice within the glacier between the site of supply of the debris from valley walls or entrainment from the glacial bed to the site of emergence onto the glacial surface. The mechanisms of entrainment and of englacial transport are beyond the scope of this paper, and are treated at length by others (see summaries in Kirkbride, 1995; Benn and Evans, 1998). Working on polythermal glaciers in Svalbard, Glasser and others (1999) and Hambrey and others (1999) claim that morainal-width increases reflect the emergence of folded and sheared debris-rich ice bands. This contrasts with the simplifying assumption made herein that the debris-rich septum remains uniform throughout its length. While the model presented is therefore not universal in its explanation of specific widening patterns, it nonetheless captures the evolution of moraines once the debris emerges. Moraines should still evolve toward a uniform and thin debris cover, and should widen beyond the borders of the underlying debris bands.

There are specific conditions that lead to strong feedbacks on glacial extent. Where talus is efficiently produced and is delivered to tributary glacier flanks by steep slopes, and where many tributary glaciers contribute to a trunk valley, strong damping of the melt rate will occur. In many high mountain ranges the glacial tongues extend far down-glacier of the limits set by local meteorology (see Kirkbride, 1995, for brief summary). The modulation of glacier extent by medial moraines not only affects long-term glacial erosion of a valley, but also affects reconstructions of paleo-ELAs using accumulation-area ratio techniques. The changes can be large, being modified from a range of $0.5-0.8$ for unmantled glaciers to 0.3-0.5 for highly mantled glaciers (Kirkbride, 1995).

\section{ACKNOWLEDGEMENTS}

I thank S. Lundstrom for generously supplying a copy of his Ph.D. dissertation on Eliot Glacier, Oregon, U.S.A., and for discussing his results. This work was supported by a grant from NASA's Surface Topography and Change program, and by a grant from the U.S. National Science Foundation
(No. OPP98-18251). The manuscript benefited greatly from reviews by E. Waddington, E. Safran, K. MacGregor and S. Anderson. I also benefited from comments made at a Northwest Glaciology meeting, in which K. Cuffey raised the issue of strain-widening. I appreciate critical reviews by $\mathrm{N}$. Glasser and an anonymous reviewer, and the editorial suggestions of M. Hambrey. This is UCSC Institute of Tectonics contribution No. 419.

\section{REFERENCES}

Benn, D. I. and D. J. A. Evans. 1998. Glaciers and glaciation. London, Arnold. Booth, D. B. and B. Hallet. 1993. Channel networks carved by subglacial water: observations and reconstruction in the eastern Puget Lowland of Washington. Geol. Soc. Am. Bull., 105(5), 671-683.

Bozhinskiy, A. N., M. S. Krass and V.V. Popovnin. 1986. Role of debris cover in the thermal physics of glaciers. F. Glaciol., 32(111), 255-266.

Driedger, C. L. 1981. Effect of ash thickness on snow ablation. U.S. Geol. Surv. Prof. Pap. 1250, 461-478.

Eyles, N. and R. J. Rogerson. 1978. A framework for the investigation of medial moraine formation: Austerdalsbreen, Norway, and Berendon Glacier, British Columbia, Canada. 7. Glaciol., 20(82), 99-113.

Gilbert, G. K. 1909. The convexity of hilltops. 7. Geol., 17, 344-350.

Glasser, N. F., M. R. Bennett and D. Huddart. 1999. Distribution of glaciofluvial sediment within and on the surface of a high Arctic valley glacier: Marthabreen, Svalbard. Earth Surf. Processes Landforms, 24(4), 303-318.

Gomez, B. and R.J. Small. 1985. Medial moraines of the Haut Glacier d'Arolla, Valais, Switzerland: debris supply and implications for moraine formation. f. Glaciol., 31 (109), 303-307.

Gudmundsson, G. H. 1999. A three-dimensional numerical model of the confluence area of Unteraargletscher, Bernese Alps, Switzerland. f. Glaciol., 45(150), 219-230.

Hambrey, M. J., M. R. Bennett, J. A. Dowdeswell, N. F. Glasser and D. Huddart. 1999. Debris entrainment and transfer in polythermal valley glaciers. 7. Glaciol., 45(149), 69-86.

Kirkbride, M. P. 1995. Processes of transportation. In Menzies, J., ed. Modern glacial environments: processes, dynamics and sediments. Vol. 1. Glacial environments. Oxford, etc., Butterworth-Heinemann, 261-292.

Lundstrom, S. C. 1992. The budget and effect of superglacial debris on Eliot Glacier, Mount Hood, Oregon. (Ph.D. thesis, University of Colorado, Boulder.)

Lundstrom, S. C., A. E. McCafferty and J. A. Coe. 1993. Photogrammetric analysis of 1984-89 surface altitude change of the partially debris-covered Eliot Glacier, Mount Hood, Oregon, U.S.A. Ann. Glaciol., 17, 167-170.

Oerlemans, J. and J. P. F. Fortuin. 1992. Sensitivity of glaciers and small ice caps to greenhouse warming. Science, 258(5079), 115-117.

Oerlemans, J. and 10 others. 1998. Modelling the response of glaciers to climate warming. Climate Dyn., 14(4), 267-274. 